\title{
Sonlu Eleman Modellerinin Maksimum Olasılık Tahmini ile Güncellenmesi
}

\author{
Çağlayan HIZAL ${ }^{1}$
}

\section{ÖZ}

Matematiksel yapı modellerinin titreşim verileri kullanılarak güncellenmesi konusu, son yıllarda giderek artan bir şekilde araştırmacıların ilgisini çekmektedir. Bu hususta literatüre sunulan yöntemler genel olarak deterministik ve olasılıksal olarak sınıflandırılmaktadır. $\mathrm{Bu}$ bağlamda hem deterministik hem de olasılıksal model güncelleme yöntemlerinin birçok varyasyonu yer almaktadır. Bu çalışmada ise maksimum olasılık tahminine dayalı alternatif bir yaklaşım sunulmaktadır. Önerilen yöntemde, modal tanılama sırasında öngörülen ölçüm hatalarının yanı sıra model hatası da boyutsuz bir Rayleigh oranı üzerinden dikkate alınmaktadır. Sisteme ait model parametreler, ölçüm ve modelleme hatalarının normal dağılım göstereceği kabulüyle oluşturulan bir olasılık yoğunluk fonksiyonu üzerinden hesaplanmaktadır. Sunulan yöntemin güvenirliği bir sayısal ve bir deneysel uygulama üzerinden değerlendirilmiştir. Elde edilen verilere göre önerilen yöntemin oldukça makul sonuçlar verdiği gözlemlenmektedir.

Anahtar Kelimeler: Model güncelleme, maksimum olasılık kestirimi, modal tanılama, çoklu ölçüm setleri.

\section{ABSTRACT}

\section{Finite Element Model Updating by using Maximum Likelihood Estimation}

In recent years, the problem of vibration-based model updating of structures has been increasingly attracting the attention of researchers. In general sense, the corresponding studies available in the literature can be classified as deterministic and probabilistic methods. In this context, various implementations are available for the deterministic and probabilistic approaches. This study, however, presents an alternative approach based on the maximum likelihood estimation. In the proposed methodology, the modelling errors are considered by using a non-dimensional Rayleigh ratio, in addition to the measurement errors. System model parameters are updated via a probability density function obtained by the assumption that the measurement and modelling errors follow normal distribution. The reliability of the proposed

\footnotetext{
Not: Bu yaz1

- Yayın Kurulu'na 21 Mayıs 2020 günü ulaşmıştır. 14 Aralık 2020 günü yayımlanmak üzere kabul edilmiştir.

- 30 Kasım 2021 gününe kadar tartışmaya açıktır.

- https://doi.org/10.18400/tekderg.739610
}

1 İzmir Yüksek Teknoloji Enstitüsü, İnşaat Mühendisliği Bölümü, İzmir - caglayanhizal@iyte.edu.tr https://orcid.org/0000-0002-9783-6511 
method has been verified by one numerical and one experimental application. According to the results, it is observed that the proposed method gives rather reasonable solution.

Keywords: Model updating, maximum likelihood estimation, modal identification, multiple measurement sets.

\section{GíRIŞ}

Son yıllarda, Yapı Sağlığı İzlemesi (Structural Health Monitoring, SHM) uygulamaları, bilimsel literatürde ve mühendislik uygulamalarında sıklıkla başvurulan bir yöntem olarak öne çıkmakta ve birçok araştırmacının giderek artan bir şekilde ilgisini çekmektedir. SHM en basit şekilde, bir mühendislik yapısının frekans, sönüm oranı, mod şekli gibi dinamik parametrelerinin belirlenmesi ve bu parametrelerdeki değişimlerden yola çıkarak, yapıya ait matematiksel modelin güncellenmesi (kalibrasyonu) ve/veya yapıda oluşabilecek hasarın yerinin ve şiddetinin tespit edilmesi şeklinde tanımlanabilir. Bu nedenle titreşim bazlı SHM uygulamalarındaki ilk adım, modal parametrelerinin tayin edildiği Modal Tanılama (Modal Identification) aşamasıdır. Bu amaç doğrultusunda literatüre kazandırılmış birçok yöntem bulunmaktadır. Bunlar arasında, Stokastik Altuzay Tanılaması (Sthocastic Subspace Identification, SSI) [1], Frekans Alanı Ayrıklaştırması (Frequency Domain Decomposition, FDD) [2] gibi deterministik ve Maksimum Olasılık Kestirimi (Maximum Likelihood Estimation, MLE) [3], Bayesyen Operasyonel Modal Analiz (Bayesian Operational Modal Analysis, BAYOMA) yöntemleri [4,5] gibi olasılıksal tabanlı yaklaşımlar ve bunların çoklu ölçüm grupları, çakışık mod etkisi vb. durumların çözümüne yönelik olarak geliştirilen varyasyonları [6-8] literatürde en çok bilinen ve sık başvurulan Modal Tanılama yöntemleri olarak öne çıkmaktadır.

Modal tanılamadan sonraki aşamalarda ise, belirlenen modal parametreler esas alınarak, incelenen yapıya ait sonlu elemanlar modelinin güncellenip, bu modellerin kıyaslanmasıyla yapıda oluşan hasarların şiddeti ve yeri tespit edilebilir. Buradaki en temel yaklaşım, tanilanan modal parametreler ile sonlu elemanlar modelinden elde edilen modal parametreler arasındaki hata için, ağırlıklı en küçük kareler yaklaşımıyla oluşturulan bir amaç fonksiyonun minimizasyonu prensibine dayanmaktadır [9]. Bu temel yaklaşımda, model ve deneysel sonuçlar arasındaki fark esasen tahmin ve modelleme hatalarının toplamı olarak ifade edilmektedir. Buradaki tahmin hatası, kullanılan modal tanılama tekniğinden kaynaklanan hataları (sensör ve/veya kanal gürültüsü veya kullanılan teknikten kaynaklı), model hataları ise kullanılan sonlu eleman model güncelleme tekniğinden ve/veya rijitlik ve kütle matrislerinin parametrik modellenmesinden kaynaklanan kusurları tanımlamaktadır [10]. Bu tür model güncelleme problemlerinin uygulanmasında karşılaşılan en önemli sorun ise uygulanan en küçük kareler yaklaşımında kullanılacak ağrılıkların belirlenmesidir. Bu açıdan, bu ağırlıkları modal parametrelere ait belirsizliklerle ilişkilendiren Stokastik yöntemler oldukça makul sonuçlar vermektedir. Pertürbasyon ve Bayesyen temelli MonteCarlo simülasyonu gibi yaklaşımlara dayalı çalışmalar, Stokastik yöntemlerin en bilinen ve öncül yaklaşımlarıdır. Burada, Monte-Carlo bazlı yöntemler, özellikle parametrik belirsizliklerin yüksek olması durumunda, oldukça makul sonuçlar vermekle birlikte, analiz süresi açısından dikkate değer ölçüde dezavantajlı olmaktadır [11-14]. Pertürbasyon temelli yöntemler ise, yüksek parametrik belirsizlik durumu için, Monte-Carlo yöntemlerine nazaran daha rraksak sonuçlar vermekle birlikte analiz süresini oldukça makul bir seviyeye 
düşürebilmektedir [15-17]. Bunun dışında, Hiyerarşik Bayesyen Model Güncelleme (Hierarchical Bayesian Model Updating) yöntemleri de son yıllarda birçok araştırmacının ilgisini kazanmıştır [18,19]. Hiyerarşik Bayesyen yöntemleri, parametrik belirsizliklerin farklı zamanlarda, farklı çevresel ve ortamsal etkiler altında alınan çok sayıda ölçüm verisi üzerinden hesaplanmasını temel almaktadır. Bu açıdan bakıldığında, Hiyerarşik Bayesyen yöntemlerinin, ölçüm hatalarından kaynaklanabilecek belirsizliklerden çok modelleme hatalarından kaynaklanan belirsizliklere odaklandığı söylenebilir. Diğer yandan, parametrik belirsizliklerin, model ve ölçüm hatalarıyla ilişkilendirildiği ve bu belirsizliklerin BAYOMA ile belirlendiği bazı iki aşamalı yöntemler de literatürde mevcuttur [20-24].

$\mathrm{Bu}$ çalışmada, sonlu eleman modellerinin maksimum olasılık tahmini ile güncellenmesi için alternatif bir yaklaşım sunulmaktadır. Esasen sunulan yöntem, literatürdeki birçok olasılıksal yaklaşımla benzerlik göstermektedir. Bununla birlikte, mevcut yöntemlerden farklı olarak model hatası boyutsuz bir Rayleigh oranı vasıtasıyla dikkate alınmaktadır. Ölçüm ve model hatalarına ait belirsizlikler ise çoklu ölçüm setleri üzerinden hesaplanmaktadır. Bu bağlamda, sunulan yöntemin etkinliği sayısal ve deneysel analizlerle farklı açılardan test edilmektedir.

\section{TEORIKK ARKA PLAN VE FORMULASYON}

Yapı sağlığı izlemesinde modal parametrelerin tayini, yapının dinamik karakteristiklerinin kestirilebilmesi açısından oldukça büyük önem arz etmektedir. Malzeme ve ekipman eksikliği nedeniyle, çoğu zaman yeterli sayıda ölçüm verisi elde edilememektedir. Bu durumda, ölçüm lokasyonu ve sayısı, elde edilen parametrelin kalitesini olumsuz yönde etkilemekte ve matematiksel modelin tamamını (veya büyük bir kısmını) yansıtacak parametrelerin elde edilmesi oldukça zor bir hale gelmektedir. Bu nedenle, titreşim esaslı model güncelleme problemlerinde, ilk aşamada mümkün olduğunca çok modal parametrenin makul bir yakınsaklıkla elde edilmesi beklenmektedir. İkinci aşamada ise, eldeki matematiksel modelin ölçümlerden elde edilen dinamik parametrelerle uyumlu hale getirilmesi gerekmektedir. Matematiksel modeli $N$ adet serbestlik derecesine sahip bir yapının, $n$ adet serbestlik derecesine ait ölçüm verisinin bulunması durumunda, $i$ 'nci moda ait analitik ve deneysel (veya operasyonel) modal parametreleri arasındaki ilişki aşağıdaki gibi yazilabilir [23].

$$
\begin{aligned}
& \frac{\boldsymbol{\Gamma} \boldsymbol{\Phi}_{i}(\theta)}{\left\|\boldsymbol{\Gamma} \boldsymbol{\Phi}_{i}(\theta)\right\|}=\alpha_{i}(\theta) \hat{\boldsymbol{\varphi}}_{i}+e_{\varphi_{i}} \\
& \omega_{i}(\theta)=\hat{\omega}_{i}+e_{\omega_{i}}
\end{aligned}
$$

Burada $\boldsymbol{\Phi}_{i}(\theta) \in R^{N \times 1}, \widehat{\boldsymbol{\varphi}}_{i} \in R^{n \times 1}$ sırasıyla analitik ve tanılanan modal şekil vektörlerini, $\omega_{i}(\theta)$ ve $\widehat{\omega}_{i}$ ise analitik ve deneysel doğal açısal frekans değerlerini göstermekte olup $\theta \in$ $R^{n_{\theta} \times 1}$ modele ait rijitlik parametrelerini temsil etmektedir. Bunun dışında, $\Gamma \in R^{n \times N}$ matematiksel modele ait tüm serbestlik dereceleri ile ölçülen serbestlik dereceleri arasındaki ilişkiyi gösteren bir gözlem matrisini, $e_{\boldsymbol{\varphi}_{i}}$ ve $e_{\boldsymbol{\omega}_{i}}$ ise analitik ve tanılanan modal parametreler arasındaki hatayı temsil etmektedirler. Denklem (1)'de yer alan $\alpha_{i}(\theta)$ katsayısı ise analitik ve tanılanan mod şekilleri arasındaki (her iki mod şekil vektörünün 1 birim büyüklüğe sahip 
olacak şekilde normalize edilmesi kaydıyla) modal güvence kriterine (Modal Assurance Criterion, MAC) karşılık gelmektedir.

$$
\alpha_{i}(\theta)=\frac{\hat{\boldsymbol{\varphi}}_{i}^{T} \boldsymbol{\Gamma} \boldsymbol{\Phi}_{i}(\theta)}{\left\|\boldsymbol{\Gamma} \boldsymbol{\Phi}_{i}(\theta)\right\|} ; \quad\left\|\boldsymbol{\Phi}_{i}(\theta)\right\|=\|\hat{\boldsymbol{\varphi}}\|=1
$$

Rijitlik parametreleri, $\theta$, aslında sistemin alt elemanlarının (çubuk, alansal vb. sonlu eleman) nominal (eldeki verilerle hesaplanabilen) değerlerini ölçekleyen normalizasyon kat katsayılarını içermektedir. Örneğin, $n_{\theta}$ adet eksenel çubuk elemandan meydana gelen $N$ adet serbestlik dereceli bir yapının rijitlik matrisi parametrik olarak aşağıdaki gibi ifade edilebilir.

$$
\mathbf{K}(\theta)=\mathbf{K}_{0}+\sum_{i=1}^{n_{\theta}} \theta_{i} \mathbf{K}_{i}
$$

Burada $\mathbf{K}(\theta) \in R^{N \times N}$ matematiksel modele ait global rijitlik matrisini, $\mathbf{K}_{0} \in R^{N \times N}$ rijitlik matrisinin parametrik olmayan bölümünü, $\mathbf{K}_{i} \in R^{N \times N}$ ise yalnızca $i$ 'nci çubuk elemanın rijitliğini içeren alt sistem rijitlik matrisini ve $\theta_{i}$ alt sisteme ait rijitlik ölçekleme parametresini göstermektedir. Yapıya ait matematiksel modelin güncel olması durumunda, yani ölçüm verileri ile elde edilen model nominal değerlerle tamamen uyumlu ise, $\theta_{i}=1$, olacaktır. Aksi takdirde de $\theta_{i} \mathbf{K}_{i}$ çarpımında, $\mathbf{K}_{i}$ matrisi tekrar $\theta_{i}=1$ olacak şekilde normalize edilebilir ( $\mathbf{K}_{i}=\theta_{i} \mathbf{K}_{i}$ şeklinde). Bu durumda, bir sonraki model güncelleme işleminde $\theta_{i}$ 'nin 1 'den farklı bir değer alması, ilgili elemanın rijitliğinde bir değişim olduğunu açıkça gösterir (örneğin $\theta_{i}<1$ olması, i’nci elemanda bir hasar yani rijitlik kaybı oluştuğunu ifade eder). Daha spesifik olarak anlatmak gerekirse, taşıyıcı sistemdeki bir kolon/perde veya kiriş elemanındaki hasar durumu $\theta_{i}$ ' deki değişim gözlemlenerek direkt olarak belirlenebilir. Örneğin, bir kolon elemanın üst ve alt uçlarındaki plastik mafsal oluşumunu gözlemlemek amacıyla, kolon uçlarına yarı rijit yaylar tanımlanıp Denklem (3) kullanılarak global rijitlik matrisi yazılırsa, bu eleman için, kolonun üst ve alt uçlarındaki dönme ve ötelenme rijitliklerini temsil eden toplam 2 adet $\theta_{i}$ parametresi bulunur [25]. Ĕger elde kalibre edilmiş bir model varsa, $\theta_{i}=1$ olarak kabul edilebilir. Kalibre edilmiş modelde hasar meydana gelmesi durumunda, örneğin bir deprem hareketi sonrası kolonun alt veya üst ucunda plastik mafsallaşma görülmüşse, yapılacak model güncelleme işleminden sonra $\theta_{i}, 1$ 'den küçük bir değer alır (hatta tamamen mafsallaşmış ise $\theta_{i} \approx 0$ olması beklenir.).

Deneysel veya operasyonel modal analiz uygulamalarında, modal frekanslar mod şekillerine nazaran daha kolay bir şekilde belirlenebilmektedir. Aynı şekilde, modal analiz ile tespit edilen doğal frekanslara ait, ölçümlemeden ve kullanılan modal tanılama tekniğinden kaynaklanabilecek belirsizliklerin de mod şekline nazaran oldukça makul ve düşük bir seviyede kaldığı bilinmektedir. Bu nedenle, literatürdeki bazı uygulamalarda modal frekanslara ait hata ihmal edilmekte, bir başka deyişle matematiksel model, modal tanılama ile elde edilenlerle aynı frekans değerlerine sahip olmaya zorlanmaktadır. Bu çalışmada da benzer bir yol izlenerek, modal frekanslara ait hata ihmal edilmektedir $\left(e_{\omega_{i}}=0\right)$. Böylece, model güncelleme problemi yalnızca mod şekillerindeki hatanın minimizasyonu üzerine inşa edilebilir. Ancak bu durumda da analitik ve ölçümlenen mod şekillerinin birbirleriyle 
eşleşme problemi ortaya çıkabilir. Özellikle, tanılama sırasında bazı modların gözden kaçırılması veya kestirilememesi durumunda ortaya çıkan bu problemin çözümü için ise aşağıdaki öz değer-öz vektör denklemi kullanılarak elde edilen bir modelleme hatası problemin içine entegre edilebilir.

$$
\left(\mathbf{K}(\theta)-\lambda_{i} \mathbf{M}\right) \boldsymbol{\Phi}_{i}(\theta)=\mathbf{0}
$$

Burada M matematiksel modele ait kütle matrisini, $\lambda_{i}$ ise sisteme ait $i$ 'nci öz değeri göstermektedir $\left(\lambda_{i}=\omega_{i}^{2}\right)$. Çoğu kez incelenen yapıya ait kütle matrisinin gerçeğine uygun (veya olabildiğince yakın) elde edilmesi, rijitlik matrisine nazaran daha kolay olmaktadır. Bu nedenle kütle matrisinin belirsizliği ihmal edilerek yalnızca rijitlik matrisine ait parametrelerin tayini üzerine gidilebilir. Denklem (4), alternatif olarak aşağıdaki şekilde düzenlenerek standart bir öz değer - öz vektör problemine dönüştürülebilir.

$$
\hat{\boldsymbol{\varphi}}_{i}^{T} \boldsymbol{\Gamma} \mathbf{E}(\theta)=\hat{\lambda}_{i} \hat{\boldsymbol{\varphi}}_{i}^{T} \boldsymbol{\Gamma}
$$

Burada, $\mathbf{E}(\theta)=\mathbf{M}^{-1} \mathbf{K}(\theta)$, olarak ifade edilmektedir. Denklem (5)'ün her iki tarafı, sağ $\operatorname{taraftan} \boldsymbol{\Gamma}^{T} \widehat{\boldsymbol{\varphi}}_{\boldsymbol{i}}$ ile çarpılıp bir model hatası ilave edilirse aşağıdaki denklem elde edilir.

$$
\beta_{i}(\theta)=1+e_{m, i}
$$

Burada $e_{m, i}$ model hatasını göstermektedir. $\beta_{i}(\theta)$ katsayısı ise boyutsuz bir Rayleigh oranını göstermekte olup aşağıdaki gibi yazılır.

$$
\beta_{i}(\theta)=\frac{\hat{\boldsymbol{\varphi}}_{i}^{T} \boldsymbol{\Gamma} \mathbf{E}(\theta) \boldsymbol{\Gamma}^{T} \hat{\boldsymbol{\varphi}}_{i}}{\hat{\lambda}_{i} \hat{\boldsymbol{\varphi}}_{i}^{T} \boldsymbol{\Gamma} \boldsymbol{\Gamma}^{T} \hat{\boldsymbol{\varphi}}_{i}}=\hat{\lambda}_{i}^{-1} \hat{\boldsymbol{\varphi}}_{i}^{T} \boldsymbol{\Gamma} \mathbf{E}(\theta) \boldsymbol{\Gamma}^{T} \hat{\boldsymbol{\varphi}}_{i}
$$

\section{MAKSIMUM OLASILIK TAHMINININ UYGULANMASI}

Denklem (1) ve (6)'de verilen eşitlikler, sırasıyla modal tanılama ve modelleme (veya mod eşleştirme) sırasında oluşabilecek hataları temsil etmekte olup matematiksel modele ait rijitlik parametrelerinin, bu hataların olasılıksal dağılımı vasıtasıyla tahmini mümkün olabilmektedir. Literatürde, bu problemin çözümü için sıklıkla bir Bayes' çıkarımı kullanılmaktadır. Bayesyen yöntemlerin en önemli avantajı, model ve tanılama hataları ile rijitlik parametrelerinin ilksel olasılık dağılımlarını kullanarak, yine rijitlik parametrelerine ait marjinal sonsal dağılımların elde edilebilmesidir. Bu durum aşağıdaki denklemler vasıtasıyla daha net bir şekilde açıklanabilir. 


$$
\begin{aligned}
& p(\theta \mid \mathbf{e}, \hat{\boldsymbol{\varphi}})=\frac{p(\mathbf{e} \mid \theta, \hat{\boldsymbol{\varphi}}) p(\theta, \hat{\boldsymbol{\varphi}})}{p(\mathbf{e})} \\
& \bar{p}(\theta)=\iint p(\theta \mid \mathbf{e}, \hat{\boldsymbol{\varphi}}) \operatorname{ded} \boldsymbol{\varphi}
\end{aligned}
$$

Burada, $p(\theta \mid \mathbf{e}, \widehat{\boldsymbol{\varphi}})$ rijitlik parametrelerine ait marjinal sonsal olasılık dağılım fonksiyonunu göstermekte olup, e ve $\widehat{\boldsymbol{\varphi}}$ aşağıdaki gibi yazılır.

$$
\begin{aligned}
& \hat{\boldsymbol{\varphi}}=\left[\hat{\boldsymbol{\varphi}}_{1}, \ldots ., \hat{\boldsymbol{\varphi}}_{N_{m}}\right] \in R^{n \times N_{m}} \\
& \mathbf{e}=\left[\left\{e_{m, 1}, e_{\hat{\boldsymbol{\varphi}}_{1}}\right\} \ldots . \quad,\left\{e_{m, N_{m}}, e_{\hat{\boldsymbol{\varphi}}_{N_{m}}}\right\}\right] \in R^{1 \times 2 N_{m}}
\end{aligned}
$$

Burada, $N_{m}$ tanılanan mod sayısını temsil etmektedir. Bayesyen modal güncelleme yöntemlerinin uygulanmasındaki en büyük problem, Denklem (8)'in sol tarafinda yer alan sonsal dağılımın hesaplanması ve Denklem (9)'da verilen ve oldukça karmaşık yapıda olan integralin çözümüdür. Bu amaçla Markov Zinciri Monte Carlo Simülasyonu'nu (Markov Chain Monte Carlo Simulation, MCMC) esas alan birçok çalışma, çeşitli araştırmacilar tarafından literatüre sunulmuştur. Bayesyen model güncelleme problemini, MCMC prosedürüne gerek duymayan ve ölçüm hatalarını Bayesyen Modal Operasyonel Modal Analiz (BAYOMA) yöntemiyle ilişkilendirerek hesaba katan, çok daha kullanışlı aynı zamanda etkili yaklaşımlar da mevcuttur. Bu çalışmada ise, en olası rijitlik parametreleri direkt olarak $p(\mathbf{e} \mid \theta, \widehat{\boldsymbol{\varphi}})$ 'nin $\theta$ 'ya göre maksimizasyonu ile elde edilmektedir. Esasen birçok Bayesçi uygulamada, Denklem (9)'de yer alan ilksel olasılığın, düzgün dağılım (uniform distribution) göstermeleri durumunda ihmal edilebileceği ön görülmektedir. Bu durumda rijitlik parametrelerine ait sonsal olasılık dağılımın, $p(\mathbf{e} \mid \theta, \widehat{\boldsymbol{\varphi}})$ ile doğru orantılı olduğu kabul edilebilir. Böylece bu çalışmada önerilen çözüm yöntemi, bu yönüyle Bayesçi yaklaşımlarla da örtüşmektedir. Ancak önerilen yöntemde, rijitlik parametrelerine ait sonsal marjinal dağılımların elde edilmesi öngörülmemekte, dolayısıyla da yöntem belirlenen parametrelere ait sonsal belirsizliklere ait herhangi bir bilgi de sunmamaktadır. Burada yalnızca, $p(\mathbf{e} \mid \theta, \widehat{\boldsymbol{\varphi}})^{\prime}$ 'yı maksimize eden en olası rijitlik parametrelerinin belirlenmesi amaçlanmaktadır. $\mathrm{Bu}$ amaçla, $p(\mathbf{e} \mid \theta, \widehat{\boldsymbol{\varphi}})$ fonksiyonu aşağıdaki gibi yazılabilir.

$$
p(\mathbf{e} \mid \theta, \hat{\boldsymbol{\varphi}})=\prod_{i=1}^{N_{m}} p_{i}\left(e_{\hat{\varphi}_{i}} \mid \theta, \hat{\boldsymbol{\varphi}}_{i}\right) p_{i}\left(e_{m, i} \mid \theta, \hat{\boldsymbol{\varphi}}_{i}\right)
$$

Burada $p_{i}\left(e_{\widehat{\boldsymbol{\varphi}}_{i}} \mid \theta, \widehat{\boldsymbol{\varphi}}_{\boldsymbol{i}}\right)$ ve $p_{i}\left(e_{m, i} \mid \theta, \widehat{\boldsymbol{\varphi}}_{\boldsymbol{i}}\right)$ olasılık yoğunluk fonksiyonları, $e_{\boldsymbol{\varphi}_{i}}$ ve $e_{m, i}$ 'nin normal dağılıma sahip oldukları kabul edilerek aşağıdaki gibi yazılabilir. 


$$
\begin{aligned}
& p_{i}\left(e_{\hat{\boldsymbol{\varphi}}_{i}} \mid \theta, \hat{\boldsymbol{\varphi}}_{i}\right)=\frac{1}{\sqrt{2 \pi} \sigma_{\hat{\boldsymbol{\varphi}}_{i}}} \exp \left(-\frac{J_{\hat{\boldsymbol{\varphi}}_{i}}(\theta)}{2 \sigma_{\hat{\boldsymbol{\varphi}}_{i}}^{2}}\right) \\
& p_{i}\left(e_{m, i} \mid \theta, \hat{\boldsymbol{\varphi}}_{i}\right)=\frac{1}{\sqrt{2 \pi} \sigma_{m, i}} \exp \left(-\frac{J_{m, i}(\theta)}{2 \sigma_{m, i}^{2}}\right)
\end{aligned}
$$

Denklem (12) ve (13)'de, $J_{\widehat{\varphi}_{i}}(\theta)$ ve $J_{m, i}(\theta), e_{\boldsymbol{\varphi}_{i}}$ ve $e_{m, i}$ için oluşturulan amaç fonksiyonları olup aşağıdaki gibi yazılır.

$$
\begin{aligned}
& J_{\hat{\boldsymbol{\varphi}}_{i}}(\theta)=\left\|\frac{\boldsymbol{\Gamma} \boldsymbol{\Phi}_{i}(\theta)}{\left\|\boldsymbol{\Gamma} \boldsymbol{\Phi}_{i}(\theta)\right\|}-\alpha_{i}(\theta) \hat{\boldsymbol{\varphi}}_{i}\right\|^{2} \\
& J_{m, i}(\theta)=\left[\beta_{i}(\theta)-1\right]^{2}
\end{aligned}
$$

Denklem (14), mod şekillerinin birim Öklidyen norma sahip olmaları durumunda aşağıdaki şekilde düzenlenebilir.

$$
\begin{aligned}
J_{\hat{\boldsymbol{\varphi}}_{i}}(\theta)= & \boldsymbol{\Phi}_{i}^{T}(\theta) \boldsymbol{\Gamma}^{T} \boldsymbol{\Gamma} \boldsymbol{\Phi}_{i}(\theta) /\left\|\boldsymbol{\Gamma} \boldsymbol{\Phi}_{i}(\theta)\right\|^{2}-2 \alpha_{i}(\theta) \boldsymbol{\Phi}_{i}^{T}(\theta) \boldsymbol{\Gamma}^{T} \hat{\boldsymbol{\varphi}}_{i} /\left\|\boldsymbol{\Gamma} \boldsymbol{\Phi}_{i}(\theta)\right\| \\
& +\alpha_{i}^{2}(\theta) \hat{\boldsymbol{\varphi}}_{i}^{T} \hat{\boldsymbol{\varphi}}_{i}=1-\alpha_{i}^{2}(\theta)
\end{aligned}
$$

Denklem (11)'e ait negatif-logaritmik olasılık fonksiyonu, Denklem (15) ve (16) kullanılarak, aşağıdaki gibi elde edilir.

$$
L(\theta)=\sum_{i=1}^{N_{m}}\left\{\ln \sigma_{\hat{\varphi}_{i}}+\sigma_{\hat{\varphi}_{i}}^{-2}\left[1-\alpha_{i}^{2}(\theta)\right]+\ln \sigma_{m, i}+\sigma_{m, i}^{-2}\left[\beta_{i}(\theta)-1\right]^{2}\right\}
$$

Böylece en olası (veya optimal) rijitlik parametreleri, Denklem (17)'nin $\left\|\boldsymbol{\Phi}_{i}(\theta)\right\|=1$ ve $\left\|\widehat{\boldsymbol{\varphi}}_{i}\right\|=1$ kisitları altında minimizasyonu ile belirlenebilir.

$$
\hat{\theta}=\underset{\theta}{\arg \min }\{L(\theta)\}
$$

Burada en zorlayıcı aşama, $\sigma_{\boldsymbol{\varphi}_{i}}$ ve $\sigma_{m, i}$ standart sapma parametrelerinin belirlenmesidir. Aslında literatürdeki MCMC bazlı uygulamanın amacı da bu parametrelerin tahmini üzerinedir. $\mathrm{Bu}$ amaçla birçok simülasyon datası oluşturulmakta ve uygun bir örnekleme 
tekniği ile (Gibbs sampler veya Metropolis-Hasting vb.) standart sapma parametreleri ve ardından sonsal olasılık dağılım hesaplanabilmektedir. Ancak bu yöntem, problemin çözüm sürecini oldukça zorlayıcı ve zaman alıcı bir hale gelebilmektedir. Daha önce de belirtildiği üzere, bu zorlayıcı uygulamanın yerine yalnızca tek bir ölçüm setinin kullanıldığı, daha kullanışlı ve oldukça etkili Bayesyen yöntemler de mevcuttur. Ancak bu yöntemler de modal tanılama sırasında yine Bayes temelli modal tanılama algoritmalarının kullanımına ihtiyaç duymaktadır. Bu çalışma ise kullanılan modal tanılama yönteminden bağımsız bir model güncelleme tekniği sunmayı amaçlanmaktadır. Bu bağlamda, elde fazla sayıda ölçüm setinin bulunması halinde, $\sigma_{\boldsymbol{\varphi}_{i}}$ ve $\sigma_{m, i}$ parametreleri tanılama sonuçlarından elde edilerek, Denklem (18)'de bir rijit kısıt (rigid constraint) olarak tanımlanabileceği öngörülmektedir.

Model güncelleme uygulamalarının birçoğunda, modal parametrelerin tek bir ölçüm kaydı yerine fazla sayıda ölçüm seti kullanılarak belirlenmesi oldukça yaygın olarak tercih edilmektedir. Bu durumda, çoklu ölçüm setlerinden elde edilen (tanılanan) mod şekillerine ait ikinci mertebe istatistiksel parametreler (standart sapma, varyans, vb.) kolaylikla belirlenebilir. İncelenen yapıya ait, aynı lokasyonlardan alınmış, $N_{s}$ adet ölçüm seti bulunması durumunda mod şeklinin farklı ölçüm setleri arasında normal dağılım göstereceği kabul edilebilir $\left(\widehat{\boldsymbol{\varphi}}_{i} \in N\left(0, \sigma_{\varphi_{i}}\right)\right.$ ). Böylece, tanılanan mod şekline ait olasılık yoğunluk fonksiyonu aşağıdaki gibi yazılabilir.

$$
p\left(\boldsymbol{\varphi}_{i} \mid D\right)=\prod_{k=1}^{N_{S}} \frac{1}{\sqrt{2 \pi} \sigma_{\hat{\boldsymbol{\varphi}}_{i}}} \exp \left(-\frac{\left\|\boldsymbol{\varphi}_{k i}-\hat{\boldsymbol{\varphi}}_{i}\right\|^{2}}{2 \sigma_{\hat{\boldsymbol{\varphi}}_{i}}^{2}}\right)
$$

Burada, $D$ ölçüm setleri kümesini, $\boldsymbol{\varphi}_{k, i}$, k’nci ölçüm setinde tanılanan mod şekil vektörünü, $\widehat{\boldsymbol{\varphi}}_{i}$ ise ölçüm setleri arasında mod şeklinin beklenen değerini göstermektedir. Bu durumda mod şeklinin en olası (beklenen) değeri ve kovaryans matrisi yaklaşık olarak aşağıdaki gibi elde edilebilir.

$$
\begin{aligned}
& \hat{\boldsymbol{\varphi}}_{i} \approx \frac{1}{N_{s}} \prod_{k=1}^{N_{S}} \boldsymbol{\varphi}_{k i} \\
& \mathbf{C}_{\boldsymbol{\varphi}_{i}} \approx \frac{1}{N_{s}-1} \sum_{k=1}^{N_{S}}\left(\boldsymbol{\varphi}_{k i}-\hat{\boldsymbol{\varphi}}_{i}\right)\left(\boldsymbol{\varphi}_{k i}-\hat{\boldsymbol{\varphi}}_{i}\right)^{T}
\end{aligned}
$$

Mod şeklinin standart sapması ise aşağıdaki gibi denklemle hesaplanabilir [10].

$$
\hat{\sigma}_{\varphi_{i}}=\sqrt{\frac{\operatorname{tr}\left(\mathbf{C}_{\varphi_{i}}\right)}{N-1}}
$$


Denklem (6)'da tanımlanan model hatasına ait standart sapma değeri, $\sigma_{m, i}$ için de bir Rijit kısıt tanımlamak mümkündür. Tanımlanacak olan bu kısıt, aslında optimal modele ait hatanın da hangi mertebede kalacağına dair bir sınır koymaktadır. Gerçekte ise, model hatası optimal rijitlik parametrelerine bağlı olduğundan, $\sigma_{m, i}$ için yumuşak kısıt tanımlamak daha makul bir yaklaşımdır [22]. Bir başka deyişle, $\sigma_{m, i}$ 'nin düşük mertebede tutulduğu bir Rijit kısıt tanımlamak, gerçekte model hatasının da düşük mertebede kalacağını garanti etmez [9]. Bu nedenle, sunulan bu çalışmada $\sigma_{m, i}$ için rijit bir kısıt tanımlamakla birlikte bu değer Denklem (6) üzerinden yapılan sezgisel bir çıkarımla elde edilmektedir. Bu amaçla, $\beta_{i}(\theta)$, yaklaşık olarak aşağıdaki gibi yazılabilir.

$$
\beta_{i}(\theta) \approx \hat{\lambda}_{i}^{-1} \hat{\boldsymbol{\varphi}}_{i}^{T} \boldsymbol{\Gamma}\left(\boldsymbol{\Phi}_{i}(\theta) \hat{\lambda}_{i} \boldsymbol{\Phi}_{i}^{T}(\theta)\right) \boldsymbol{\Gamma}^{T} \hat{\boldsymbol{\varphi}}_{i}=\left\{\alpha_{i}(\theta)\left\|\boldsymbol{\Gamma} \boldsymbol{\Phi}_{i}(\theta)\right\|\right\}^{2}
$$

$\mathrm{Bu}$ durumda, yapılan varsayım ile, model hatası, modal şekil vektörüyle ilişkilendirilerek mod şekline ait tahmin hatasına eşdeğer olarak kabul edilebilir $\left(\sigma_{m, i} \approx \sigma_{\varphi_{i}}\right)$. Böylece, Denklem (18)'de verilen optimizasyon denklemi aşağıdaki gibi yazılır.

$$
\hat{\theta}=\underset{\theta}{\arg \min }\left\{\sum_{i=1}^{N_{m}}\left\{2 \ln \sigma_{\hat{\boldsymbol{\varphi}}_{i}}+\sigma_{\hat{\boldsymbol{\varphi}}_{i}}^{-2}\left[2-\alpha_{i}^{2}(\theta)-2 \beta_{i}(\theta)+\beta_{i}^{2}(\theta)\right]\right\}\right\}
$$

\section{SAYISAL VE DENEYSEL UYGULAMALAR}

Bu bölümde, önerilen yöntemin sayısal ve deneysel doğrulamasına yönelik iki adet uygulama sunulmaktadır. İlk uygulamada, ölçüm seti ve hesaba katılan mod sayısının güncellenen parametrelerin kalitesine olan etkisi, 10 katlı bir kayma çerçevesine ait sayısal bir model üzerinden incelenmektedir. İkinci uygulamada ise 3 katlı bir laboratuvar modeli, ortamsal titreşim etkileri altında incelenmektedir. Bu bağlamda, tüm analizler MATLAB [26] ortamında yazılan bir bilgisayar programı vasıtasıyla gerçekleştirilmiştir.

\subsection{Sayısal Uygulama}

Bu uygulama kapsamında incelenen 10 katlı kayma çerçevesinin sayısal modeline ait temel parametreler Çizelge l'de sunulmaktadır. Burada, katlar arası ötelenme rijitliği $k=1000$ $\mathrm{kN} / \mathrm{mm}$ olarak belirlenmiştir. Kat kütleleri üniform olarak kabul edilerek, $m=250$ ton olarak seçilmiş ve sayısal modelin modal sönüm oranı, tüm modlar için $\xi=\% 1,00$ olarak kabul edilmiştir. Modelin parametrik rijitlik matrisi, Denklem (3) kullanılarak elde edilmiştir. Sayısal model, toplamda 1000 adet ölçüm seti olacak şekilde ortamsal titreşim etkilerine maruz tutulmuş ve modal parametreler bu ölçüm setlerinden elde edilen değerlerin ortalaması alınarak elde edilmiştir. Her bir ölçüm setinde sayısal model, modal uyarımın spektral yoğunluğu bütün modlar için eşit ve $1 \mu g^{2} / H z$ olacak şekilde, Gauss beyaz gürültüsüne maruz bırakılmıştır. Modelin dinamik analizi MATLAB [26] ortamında yazılan ve Newmark-Beta integrasyon yöntemini kullanan (sabit ortalama ivme kabulüyle) bir bilgisayar programı yardımıyla gerçekleştirilmiştir. Dinamik analiz sırasında, zaman adımı dt =1/10000 sn olarak 
alınmıştır. Analiz sonrasında, her bir ölçüm seti için, sayısal modelin kat seviyelerindeki ivme tepkileri $256 \mathrm{~Hz}$ örnekleme frekansı ile $300 s n(5 \mathrm{dk})$ boyunca toplanmıştır. Elde edilen ivme ölçümlerinin her biri, spektral yoğunluğu $25 \mu g^{2} / H z$ olan Gauss beyaz gürültüsüyle bozulmaya maruz bırakılmıştır. Böylece, her bir mod için uyarım sinyalinin ve kanal gürültüsünün spektral yoğunluk oranı (signal to noise ratio), $s n r=100$ olarak ayarlanmıştır.

Çizelge 1 - Sayısal modele ait temel parametreler

\begin{tabular}{ccccc}
\hline $\begin{array}{c}\text { Kat } \\
\text { Numarası, } \boldsymbol{i}\end{array}$ & $\begin{array}{c}\text { Gerçek Rijitilik } \\
\text { Parametresi, } \boldsymbol{\theta}_{\boldsymbol{i}}\end{array}$ & $\begin{array}{c}\text { Normalize Kat } \\
\text { rijitliği, } \\
\boldsymbol{k}_{\boldsymbol{i}}=\boldsymbol{k} \times \boldsymbol{\theta}_{\boldsymbol{i}} \\
(\boldsymbol{k} \boldsymbol{N} / \mathbf{m m})\end{array}$ & $\begin{array}{c}\text { Mod }) \\
\text { numarası }\end{array}$ & $\begin{array}{c}\text { Doğal } \\
\text { Titreşim } \\
\text { Frekansı, } \boldsymbol{f}_{\boldsymbol{i}} \\
\mathbf{( H z )}\end{array}$ \\
\hline 1 & 1,00 & 1000 & 1 & 1,35 \\
2 & 1,00 & 1000 & 2 & 3,63 \\
3 & 1,00 & 1000 & 3 & 6,07 \\
4 & 0,75 & 750 & 4 & 8,06 \\
5 & 0,75 & 750 & 5 & 10,32 \\
6 & 0,75 & 750 & 6 & 11,90 \\
7 & 0,50 & 500 & 7 & 13,36 \\
8 & 0,50 & 500 & 8 & 14,46 \\
9 & 0,50 & 500 & 9 & 16,33 \\
10 & 0,50 & 500 & 10 & 18,67 \\
\hline
\end{tabular}

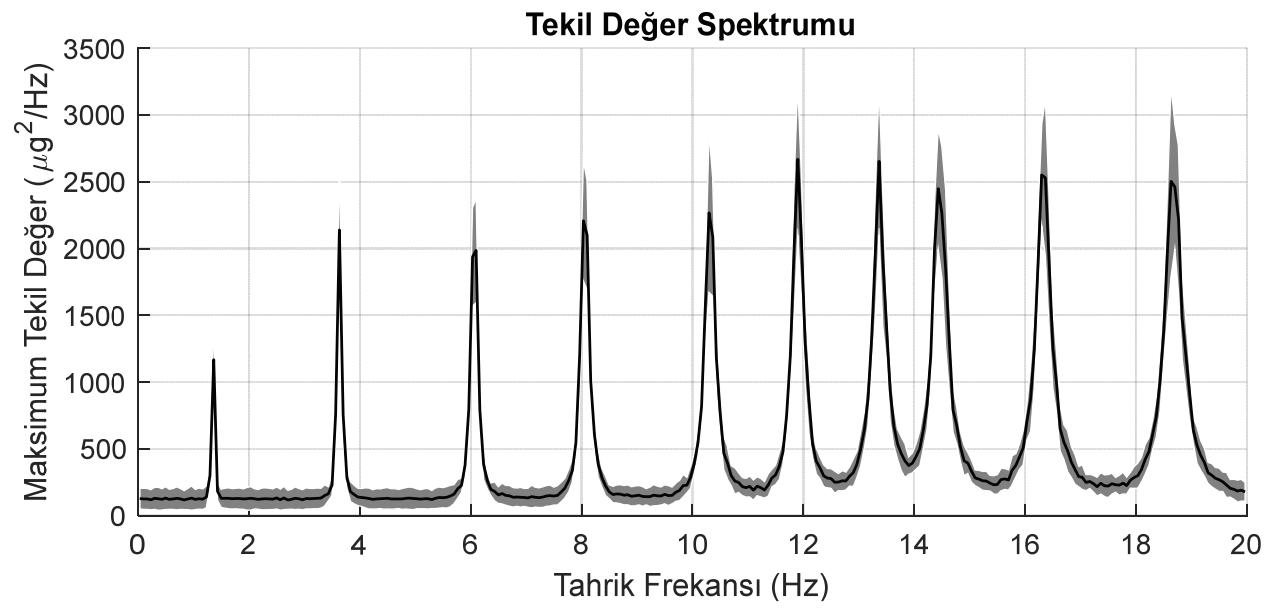

Şekil 1 - Tekil değer spektrumu: Ortalama (siyah çizgi) ve standart sapma (gri alan) 

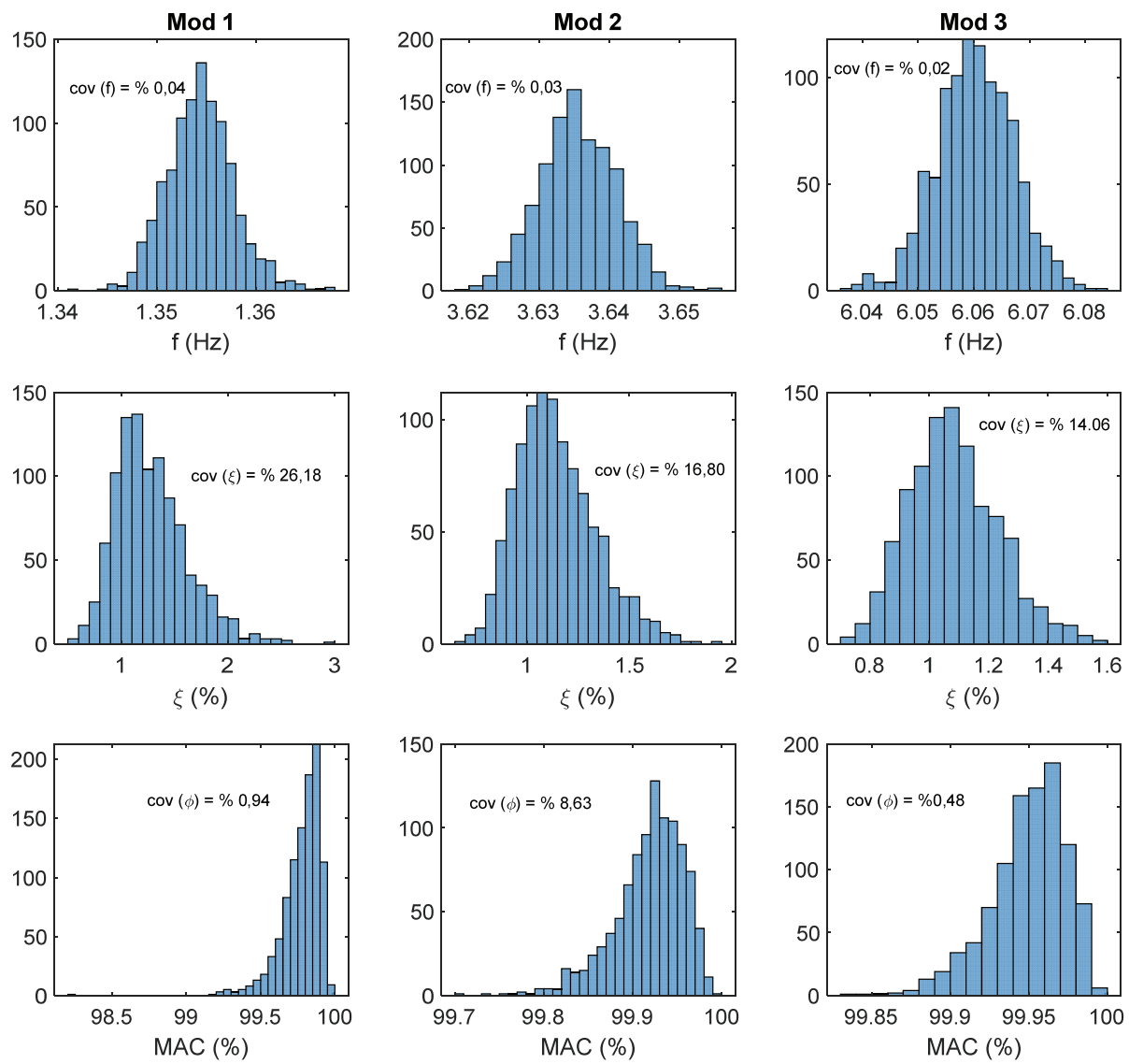

Şekil 2 - 1000 adet ölçüm seti için elde edilen ilk üç moda ait histogramlar

Ölçüm setlerinden elde edilen Tekil Değer Spektrumunun (Singular Value Spectrum) ortalama ve standart sapma değerleri Şekil l'de sunulmaktadır. İlk bakışta, gözlemlenen modal piklerin gerçek doğal frekanslarla uyumlu olduğu açıkça görülmektedir. Her bir ölçüm seti için doğal titreşim frekansları, modal sönüm oranları ve serbest titreşim mod şekilleri, Frekans ve Uzay Alanı Ayrışım Tekniği (Frequency and Spatial Domain Decomposition, FSDD) kullanılarak belirlenmiştir [27]. Elde edilen doğal frekans, modal sönüm oranı ve her bir ölçüm setinden elde edilen mod şekilleri ile bunların gerçek değerleri arasındaki MAC değerlerine ait histogramlar Şekil 2'de sunulmaktadır. Burada, aynı zamanda frekans, sönüm oranı ve mod şekilleri için elde edilen değişkenlik katsayıları (coefficient of variation, cov) da verilmektedir. Her ne kadar yapının maruz kaldığı uyarımın ve kanal gürültüsünün spektral yoğunluğu her bir ölçüm seti için aynı olsa da elde edilen modal sönüm oranları beklenenen değer etrafında, \%15-25 mertebesine varan bir değişim göstermektedir. Bununla birlikte, doğal frekans ve mod şekillerine ait değişimler karşılaştırıldığında, mod şekillerindeki belirsizliğin çok daha yüksek mertebede olduğu görülmektedir. Bu da başlangıçta yapılan, doğal frekansların katkısının ihmali kabulünü makul kılmaktadır. Daha 
spesifik olarak bakılırsa, sunulan histogramda tanılanan frekansların ve elde edilen MAC'ların beklenen değerleri ile bunların gerçek değerleri arasındaki fark, \% 0.1-0.5 mertebesinde çıkmaktadır. Modal tanılama sırasındaki tahmin hatasından kaynaklanan bu farklar hem frekans hem de mod şekilleri için oldukça küçük ve birbirine yakın mertebede olmasına rağmen, bu parametrelere ait ikinci mertebe istatistiksel değerlerdeki (standart sapma veya değişkenlik katsayısı gibi) değişim dikkate alındığında mod şekillerinde tahmin hatalarının daha yüksek olduğu görülmektedir. Bir başka deyişle, her ne kadar gerçek değere olan yakınsaklıkları arasında önemli bir fark olmasa da ölçüm setlerinden elde edilen mod şekillerinin, beklenen değer etrafındaki şaçılımı doğal frekans değerlerine nazaran daha fazladır. Aslında, uygulamada da gerçek değerler hiçbir zaman tam olarak bilinemeyeceği için, ancak standart sapma vb. istatistiksel parametreler tahmin hataları hakkında daha fazla fikir verebilir.

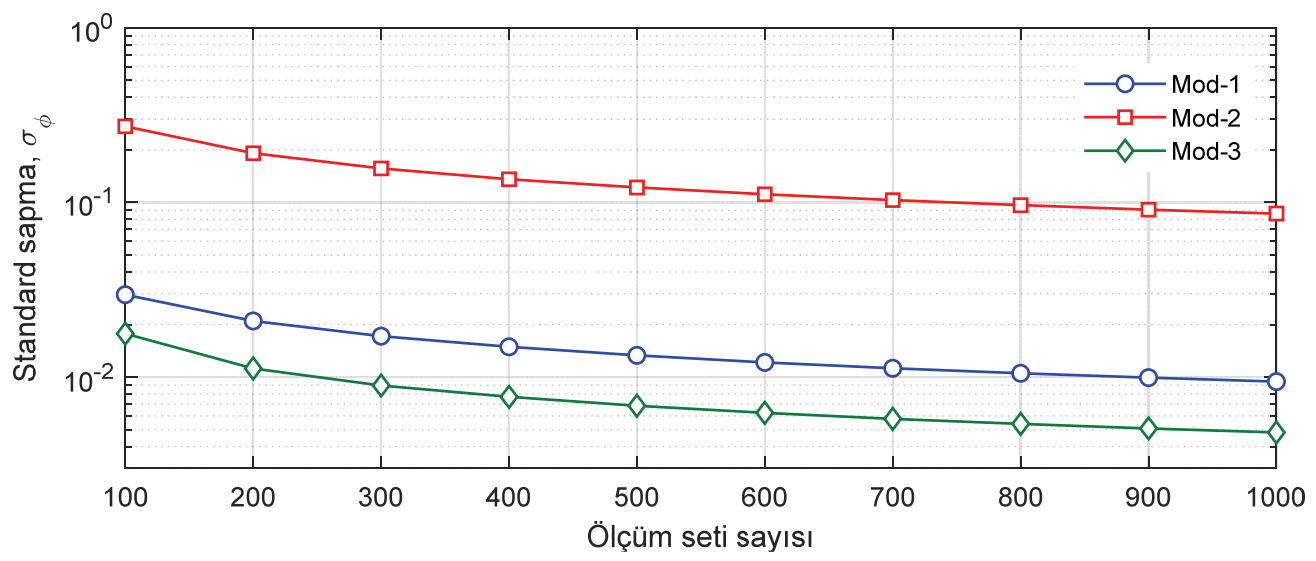

Şekil 3 - İlk üç mod şekli için elde edilen standart sapmaların ölçüm seti sayısına göre değişimi

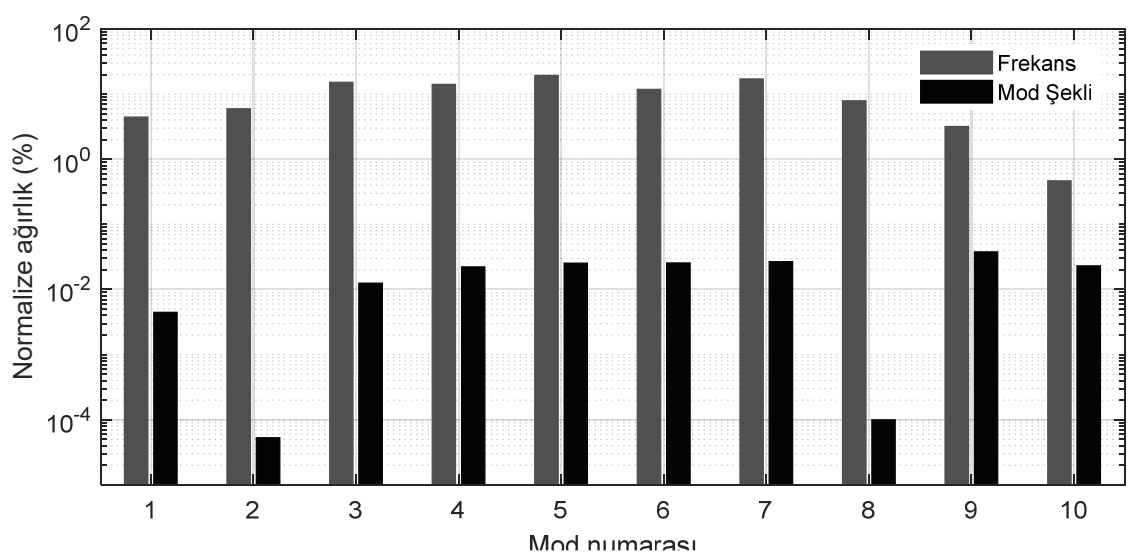

Şekil 4 - 1000 adet ölçüm seti için elde edilen mod şekilleri ve doğal frekanslara ait normalize ă̆ırlıklar 

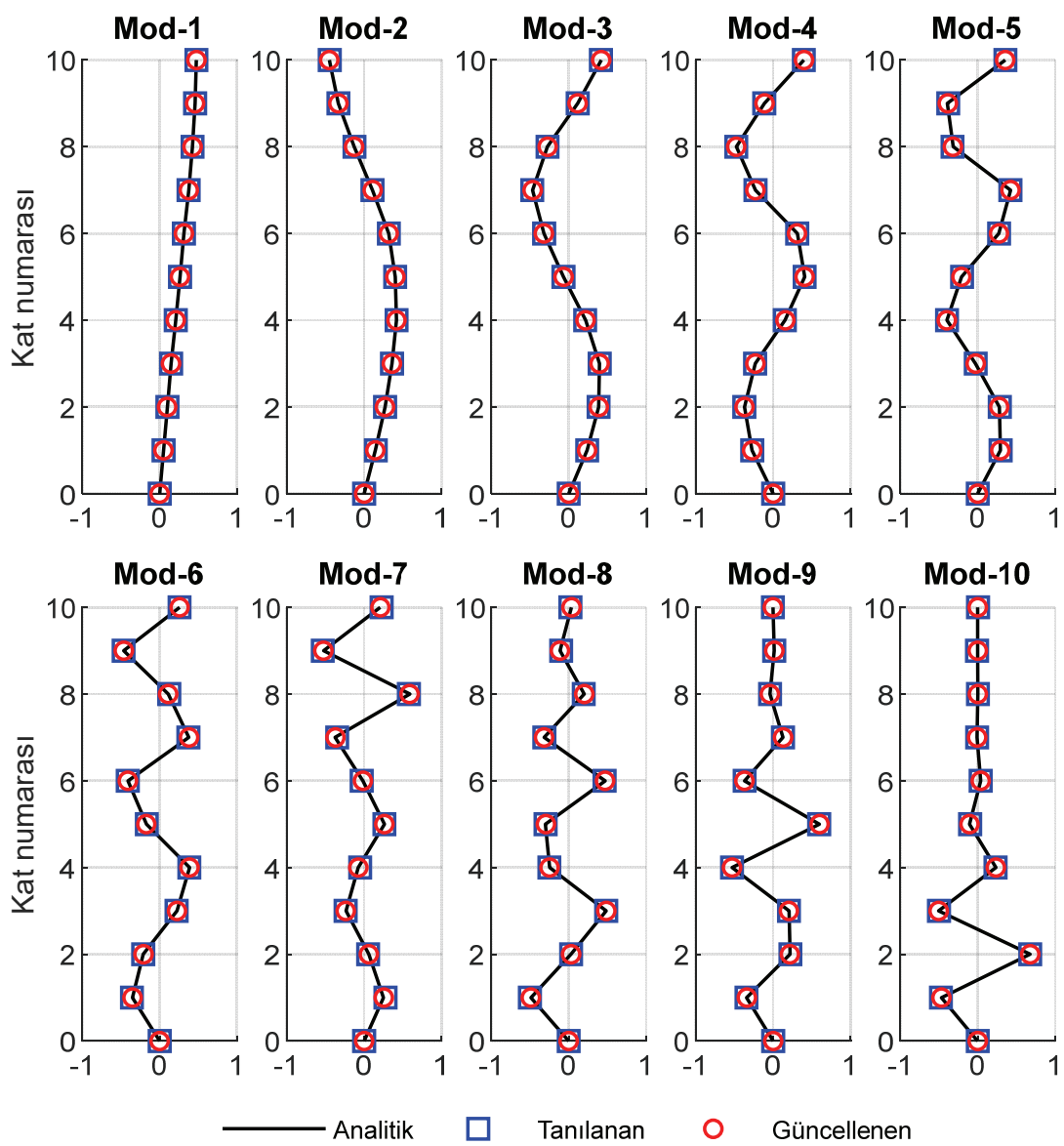

Şekil 5 - 1000 adet ölçüm seti için elde edilen mod şekilleri

İlk üç mod şekline ait standart sapmaların dikkate alınan ölçüm seti sayısına göre değişimi de Şekil 3'de sunulmaktadır. Görüldüğü üzere, ölçüm seti sayısı arttıkça beklenen mod şeklinin belirsizliği de belli bir seviyeye kadar azalmaktadır. Burada, ilk üç mod içerisinde ikinci moda ait belirsizliğin diğerlerine nazaran oldukça fazla olduğu görülmektedir. Bu da ikinci modun maksimum olasılık fonksiyonundaki ağırlığının, diğerlerine nispeten daha düşük olduğunu bir kez daha göstermektedir. Bu bağlamda, 1000 adet ölçüm seti için, doğal frekans (hesaba katılması durumunda) ve mod şekillerinin maksimum olasılık fonksiyonu içerisindeki normalize ağrılıkları Şekil 4'te sunulmaktadır. İlk bakışta, sonuçların 2. mod şeklinin olasılık fonksiyonundaki ağırlığı ile ilgili daha önce yapılan çıkarımla uyumlu olduğu görülmektedir. Burada görüldüğü üzere, doğal frekansların ağırlığı mod şekillerine nazaran çok yüksek mertebede olmaktadır.

Sayısal modelin analitik, modal tanılama ve model güncelleme elde edilen mod şekilleri Şekil 5 'de sunulmaktadır. Görüldüğü üzere, tanılanan ve güncellenen mod şekilleri analitik 
(gerçek) değerlerle mükemmel bir şekilde örtüşmektedir. Bunun dişında, hesaba katılan ölçüm seti sayısına $\left(N_{s}\right)$ göre elde edilen rijitlik parametreleri de Çizelge 2'de verilmektedir. Burada, güncellenen rijitlik parametreleri ile bunların gerçek değerleri arasındaki maksimum fark \%3-5 mertebesinde gözlemlenmektedir. Ölçüm seti sayısı arttıkça güncellenen parametrelerin kalitesinin de arttığı net bir şekilde görülmektedir. Bunun dışında, Çizelge 3 'de görüldüğü üzere, hesaba katılan mod sayısının $\left(N_{m}\right)$ güncellenen parametrelere olan etkisi daha belirgin olmaktadır. Bu örnek için, $N_{m} \geq 5$ olması durumunda güncellenen parametreler gerçek değerlere oldukça makul bir yakınsama göstermektedir.

Çizelge 2 - Güncellenen rijitlik parametrelerinin ölçüm seti sayısına göre değişimi

\begin{tabular}{ccccccccccc}
\hline \multirow{2}{*}{$\begin{array}{c}\text { Rijitlik } \\
\text { Parametresi }\end{array}$} & $\mathbf{1 0 0}$ & $\mathbf{2 0 0}$ & $\mathbf{3 0 0}$ & $\mathbf{4 0 0}$ & $\mathbf{5 0 0}$ & $\mathbf{6 0 0}$ & $\mathbf{7 0 0}$ & $\mathbf{8 0 0}$ & $\mathbf{9 0 0}$ & $\mathbf{1 0 0 0}$ \\
\hline$\theta_{1}$ & 1,00 & 0,99 & 0,99 & 0,99 & 0,99 & 0,99 & 0,99 & 0,99 & 0,95 & 0,99 \\
$\theta_{2}$ & 1,03 & 1,04 & 1,03 & 1,03 & 1,03 & 1,03 & 1,03 & 1,03 & 1,02 & 1,00 \\
$\theta_{3}$ & 0,95 & 0,96 & 0,95 & 0,95 & 0,95 & 0,95 & 0,95 & 0,96 & 0,99 & 0,99 \\
$\theta_{4}$ & 0,73 & 0,73 & 0,72 & 0,72 & 0,73 & 0,73 & 0,72 & 0,73 & 0,75 & 0,75 \\
$\theta_{5}$ & 0,74 & 0,74 & 0,74 & 0,74 & 0,74 & 0,74 & 0,74 & 0,74 & 0,72 & 0,75 \\
$\theta_{6}$ & 0,72 & 0,72 & 0,72 & 0,72 & 0,72 & 0,72 & 0,72 & 0,72 & 0,70 & 0,75 \\
$\theta_{7}$ & 0,49 & 0,49 & 0,49 & 0,49 & 0,49 & 0,49 & 0,49 & 0,49 & 0,49 & 0,50 \\
$\theta_{8}$ & 0,49 & 0,49 & 0,49 & 0,49 & 0,49 & 0,49 & 0,49 & 0,49 & 0,47 & 0,49 \\
$\theta_{9}$ & 0,50 & 0,50 & 0,50 & 0,50 & 0,50 & 0,50 & 0,50 & 0,50 & 0,49 & 0,50 \\
$\theta_{10}$ & 0,50 & 0,50 & 0,50 & 0,50 & 0,50 & 0,50 & 0,50 & 0,50 & 0,48 & 0,50 \\
\hline
\end{tabular}

Çizelge 3 - Güncellenen rijitlik parametrelerinin hesaba katılan mod sayısına göre değişimi

\begin{tabular}{ccccccccccc}
\hline \multirow{2}{*}{$\begin{array}{c}\text { Rijitlik } \\
\text { Parametresi }\end{array}$} & $\mathbf{1}$ & $\mathbf{2}$ & $\mathbf{3}$ & $\mathbf{4}$ & $\mathbf{5}$ & $\mathbf{6}$ & $\mathbf{7}$ & $\mathbf{8}$ & $\mathbf{9}$ & $\mathbf{1 0}$ \\
\hline$\theta_{1}$ & 1,03 & 1,00 & 0,91 & 1,03 & 0,99 & 1,02 & 0,97 & 0,99 & 0,98 & 0,99 \\
$\theta_{2}$ & 0,72 & 1,01 & 1,79 & 1,15 & 1,00 & 0,97 & 0,98 & 0,98 & 1,03 & 1,00 \\
$\theta_{3}$ & 0,96 & 1,06 & 0,69 & 1,63 & 0,99 & 0,98 & 0,99 & 1,00 & 0,99 & 0,99 \\
$\theta_{4}$ & 0,88 & 0,71 & 0,68 & 0,67 & 0,72 & 0,71 & 0,77 & 0,77 & 0,74 & 0,75 \\
$\theta_{5}$ & 0,62 & 0,80 & 0,69 & 0,77 & 0,75 & 0,72 & 0,72 & 0,73 & 0,74 & 0,75 \\
$\theta_{6}$ & 0,61 & 0,72 & 0,70 & 0,72 & 0,75 & 0,75 & 0,72 & 0,74 & 0,72 & 0,75 \\
$\theta_{7}$ & 0,64 & 0,52 & 0,45 & 0,49 & 0,50 & 0,49 & 0,49 & 0,49 & 0,49 & 0,50 \\
$\theta_{8}$ & 0,33 & 0,48 & 0,50 & 0,58 & 0,49 & 0,51 & 0,48 & 0,50 & 0,49 & 0,49 \\
$\theta_{9}$ & 0,55 & 0,53 & 0,50 & 0,51 & 0,50 & 0,51 & 0,50 & 0,51 & 0,50 & 0,50 \\
$\theta_{10}$ & 3,64 & 0,47 & 0,50 & 0,49 & 0,50 & 0,49 & 0,48 & 0,48 & 0,50 & 0,50 \\
\hline
\end{tabular}




\subsection{Deneysel Uygulama}

Bu kısımda, sunulan yöntemin deneysel doğrulaması 3 katlı bir laboratuvar modeli üzerinden yapılmaktadır. Söz konusu çelik model bina, daha önce Ceylan [28] tarafından kullanılmış ve sayısal modeli kurulmuştur. Yine Ceylan [28] tarafından, çelik malzemenin elastik modülü, $E=2 \times 10^{11} \mathrm{~N} / \mathrm{m}$, kat kolonlarının zayıf yöndeki atalet momenti, $I=8,333 \times 10^{-9}$ $m^{4}$ ve kat yüksekliği $0,80 m$ olarak rapor edilmiştir. Laboratuvar binasının ve binaya ait sayısal modelin görünümü Şekil 6' da sunulmaktadır.

Model bina, laboratuvar ortamında herhangi bir ilave dış uyarıma maruz kalmadan, toplamda $30 d k$ boyunca ortamsal titreşim etkilerine maruz bırakılmıştır. Kat seviyelerindeki ivme ölçümleri, $50 \mathrm{~Hz}$ örnekleme frekansıyla toplanmıştır. Ölçümlerde, $1000 \mathrm{mV} / \mathrm{g}$ hassasiyetinde ve $130 \mu g^{2} / H z$ spektral gürültü yoğunluğuna sahip toplamda 3 adet piezo-elektrik ivme ölçer kullanılmıştır. Ölçüm sistemi, 1,5 GHz CPU ve Linux işletim sistemine sahip bir dizüstü bilgisayar, 24 bit analog-dijital dönüşüme sahip 16 kanallı USBDUX-Sigma veri toplama kutusu, $120 \mathrm{~Hz}$ kesme frekansına sahip birinci dereceden bir analog alçak geçiş filtresi (low pass filter) ve ivme ölçerler için sabit bir akım kaynağından meydana gelmektedir (bkz. Şekil 7). Bunun dışında, bu düzenek kullanılarak her bir kat için elde edilen ivme ölçümleri Şekil 8 'de verilmektedir.

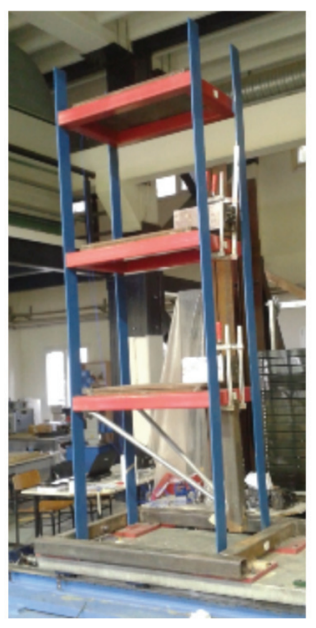

a)

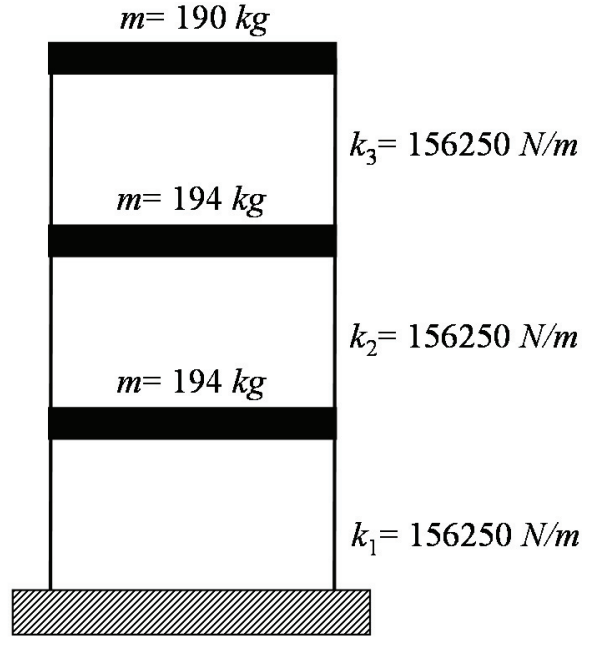

b)

Şekil 6 - a) Laboratuvar modeline ait görünüm b) Saylsal modelin şematik görünümü [28]

Yapının ivme ölçümlerden elde edilen Tekil Değer Spektrumu Şekil 9'da sunulmaktadır. Burada, 3 katlı modele ait modların yanı sıra laboratuvar binasına ait titreşim modu da görülebilmektedir. Laboratuvar binası daha önce Ceylan ve ark. [29] tarafından bir başka laboratuvar modelinin modal tanılama işlemi sırasında, zemine yerleştirilen bir ivme sensörü vasıtasıyla ölçülmüştür. Bu ölçüme ait Tekil Değer spektrumu da Şekil 9'da ayrıca sunulmaktadır. Hem 3 katlı modelden hem de laboratuvar yapısından elde edilen spektrum 
eğrilerinin $6,50 \mathrm{~Hz}$ civarında örtüşmesi, bu bölgede görünür olan modun laboratuvar binasına ait olduğunu teyit etmektedir. Ayrıca, modal tanılama ile $\left(N_{s}=25\right.$ için) elde edilen doğal frekans, sönüm oranı ve mod şekilleri ise Şekil 10' da sunulmaktadır. Burada elde edilen değerler, Ceylan [29] tarafından rapor edilen sonuçlarla makul ölçüde örtüşmektedir $\left(f_{1}=\right.$ $1,91 \mathrm{~Hz}, f_{2}=5,38 \mathrm{~Hz}, f_{3}=8,00 \mathrm{~Hz}$ ve $\left.\xi_{1}=\% 0,58, \xi_{2}=\% 0,51, \xi_{3}=\% 0,57\right)$. Bunun dişında, güncellenen mod şekillerinin de modal tanılama ile elde edilenlerle örtüştüğü görülmektedir.

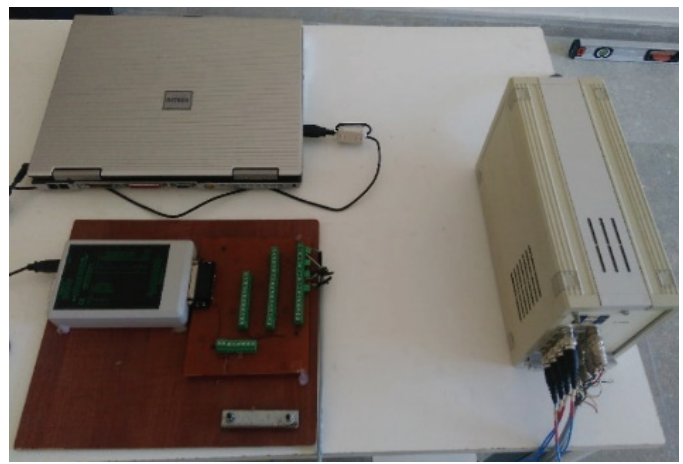

Şekil 7 - Veri toplama düzeneği
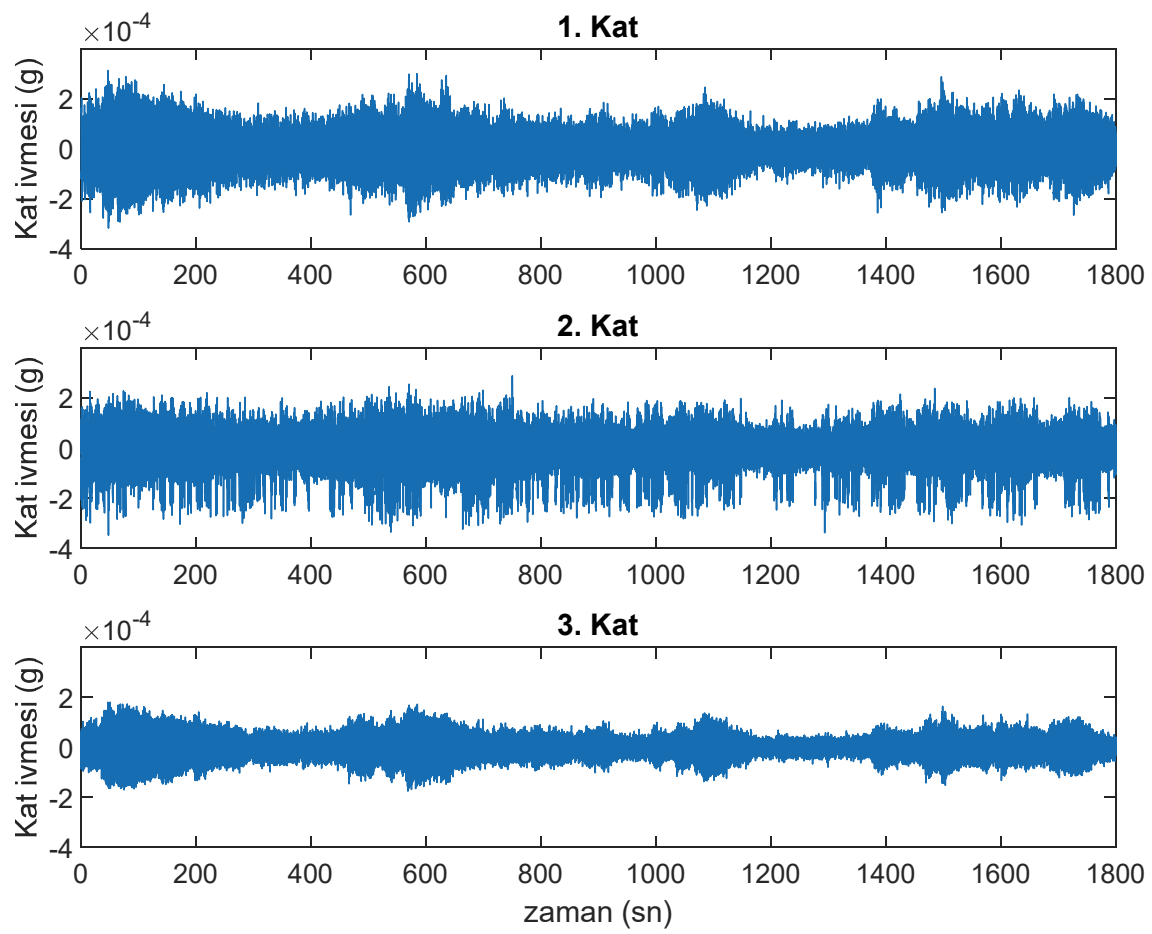

Şekil 8 - Laboratuvar modeline ait ivme ölçümleri 


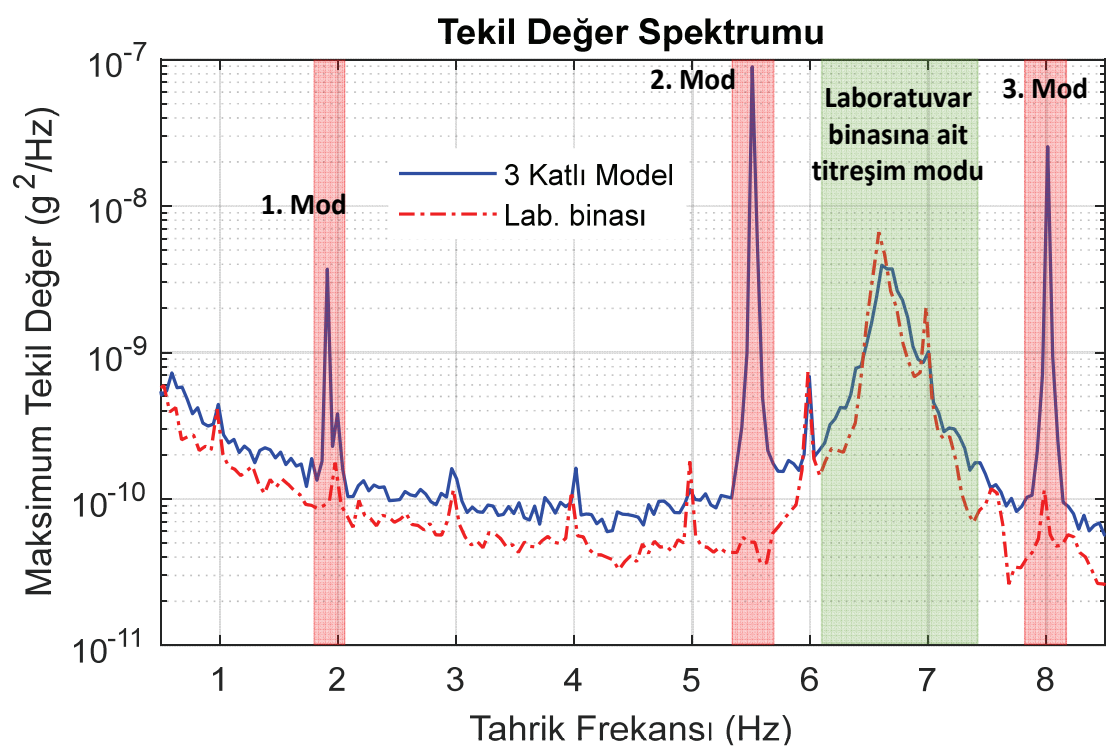

Şekil 9 - 3 katlı modelden ve laboratuvar binasından elde edilen ölçüm verilerine ait Tekil Değer spektrumları
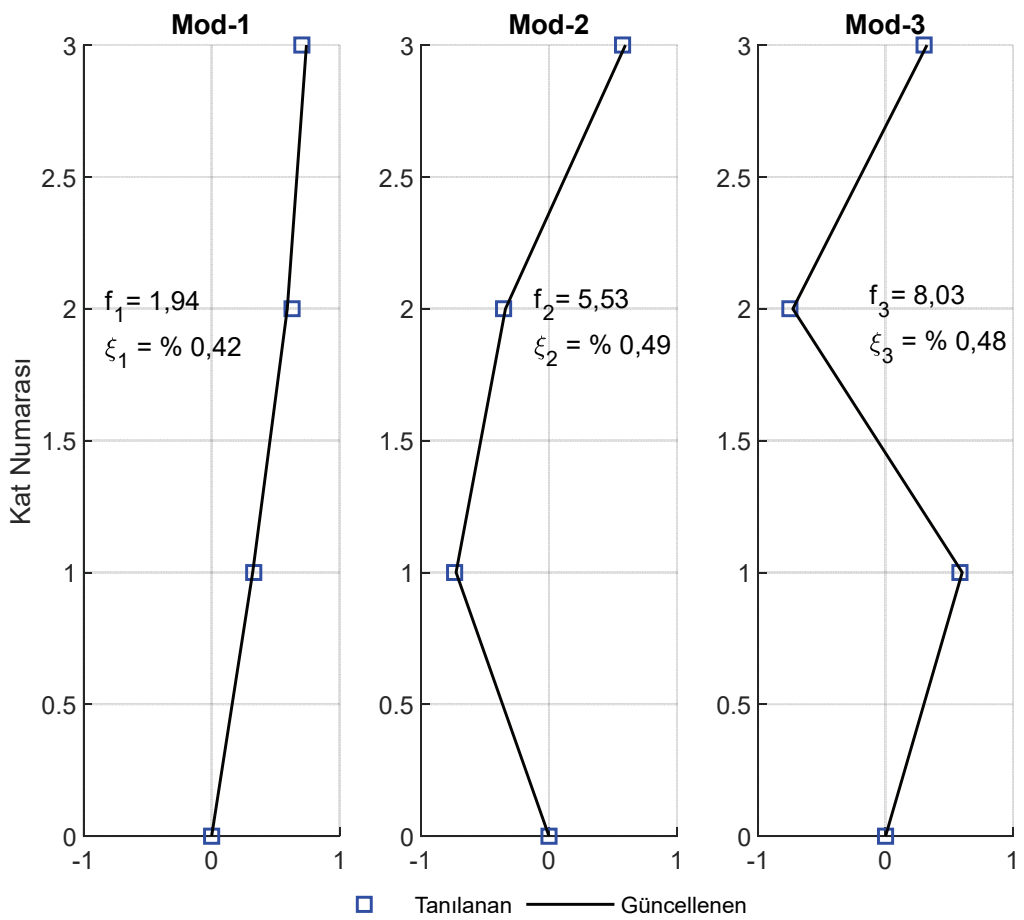

Şekil 10 - Laboratuvar modeline ait tanılanan ve güncellenen mod şekilleri 


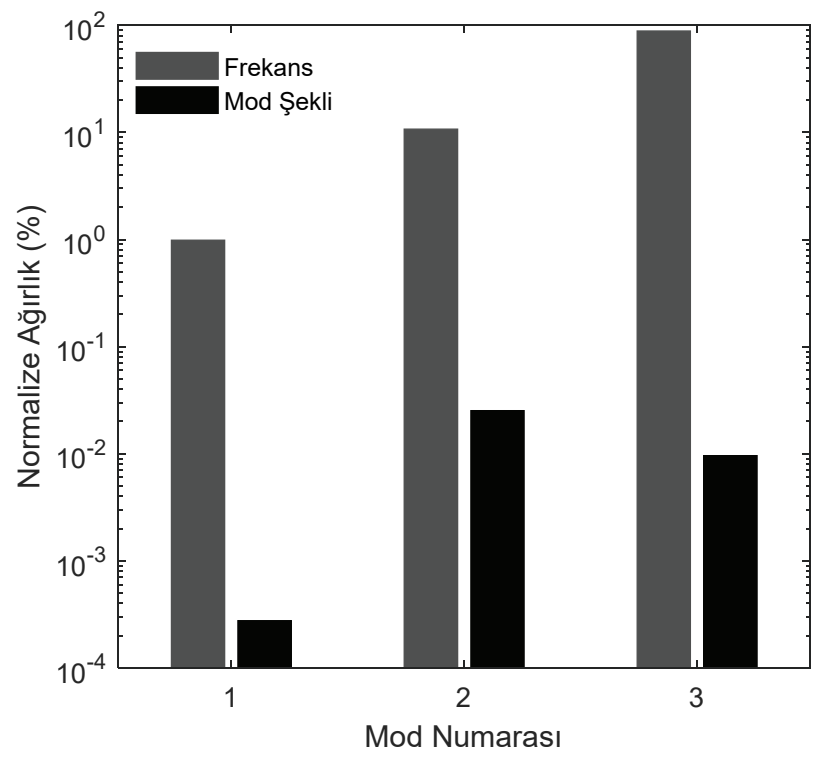

Şekil 11 - N=25 için elde edilen mod şekilleri ve doğal frekanslara ait normalize ă̆ırlıklar

Şekil 11'de doğal frekans ve mod şekillerinin, olasılık fonksiyonundaki ağırlıklarının normalize edilmiş değerleri sunulmaktadır. Sayısal örneğe benzer şekilde, doğal frekansların ağırlığının mod şekillerine nazaran çok daha yüksek olduğu belirgin bir şekilde gözlemlenebilmektedir. Bunun dışında, ölçüm seti sayısının yüksek olmasının elde edilen mod şekillerine ait ikinci mertebe istatistiksel parametrelerde (standart sapma, varyans, değişkenlik katsayısı) küçülmeye yol açtığı yani tahmin hatalarını dikkate değer oranda azalttığı bir önceki uygulamada gösterilmişti. Burada, her bir setteki ölçüm süresinin toplam ölçüm seti sayısına göre sabit kaldığı unutulmamalıdır. Deneysel uygulamada ise esasen 30 $d k$ uzunluğunda tek bir ölçüm alınmış ve bu ölçümler uygun şekilde parçalanarak ölçüm seti sayısı arttırılmıştır. Bu nedenle ölçüm seti sayısının artması, her bir setteki ölçüm süresinde kısalmaya neden olmakta, bu durum da tanılanan modal parametrelerin kalitesinde önemli ölçüde bir azalmaya yol açmaktadır.. Bu durum, mod şekilleri için hesaplanan standart sapmaların ölçüm seti sayısına göre değişimini gösteren Şekil 12 üzerinden daha iyi açıklanabilir. Şekil 12'de görüldüğü üzere, ölçüm seti sayısı 5 ile 25 arasındayken, standart sapma değeri giderek azalan bir artış göstermektedir. Ölçüm seti sayısının 25'den büyük olması durumunda ise ölçüm süresi çok fazla kısalmakta, bu durum da bazı ölçüm setlerinde tanılanan mod şekillerinin kalitesinde ciddi bir azalmaya neden olmaktadır. Böylece, $N_{s} \geq 25$ için standart sapma değerinde ani bir artış meydana gelmektedir. Bu yorumu daha da güçlendirmek amacıyla, güncellenen rijitlik parametrelerinin ölçüm seti sayısına göre değişimi Çizelge 4'de sunulmaktadır. Burada, $25 \geq N_{s} \geq 5$ aralığı için, güncellenen rijitlik parametrelerinin nominal değerlere oldukça yakın sonuçlar verdiği görülmektedir. $N_{s}=30$ olması durumunda ise, güncellenen parametreler nominal değerlerden oldukça uzaklaşmaktadır. 


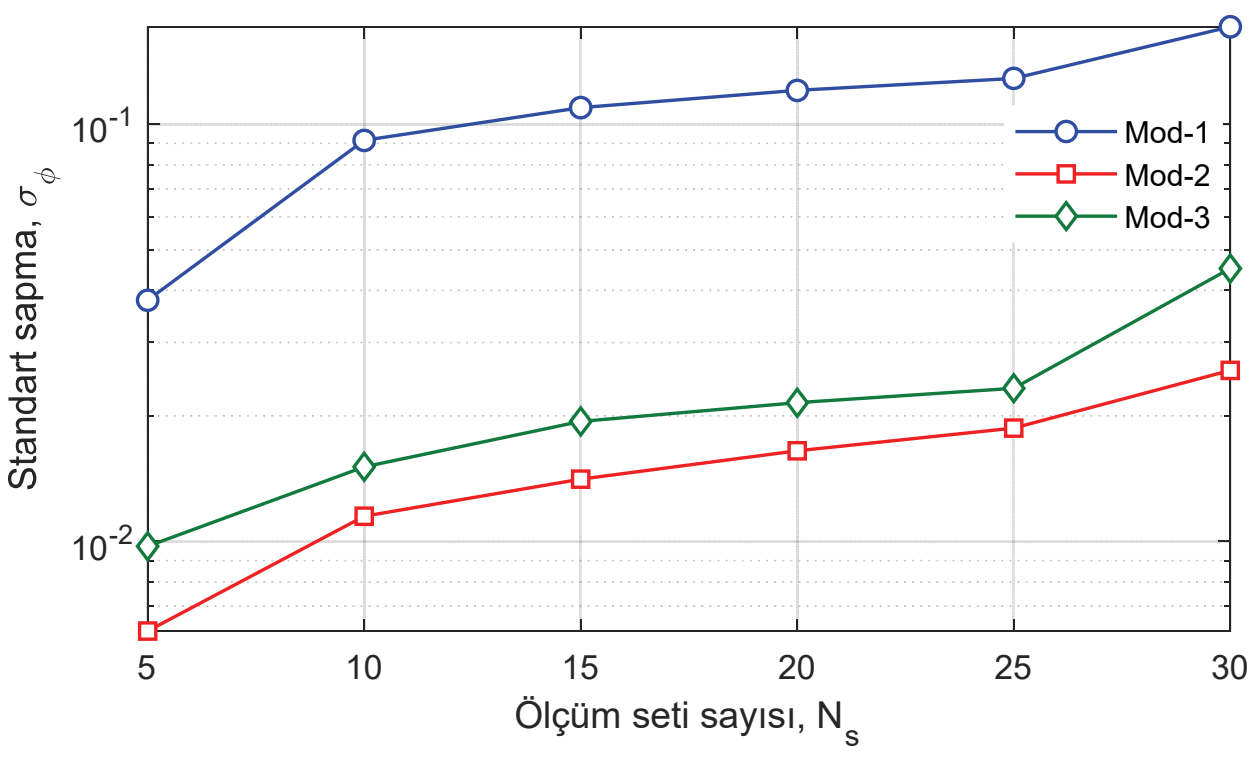

Şekil 12 - Mod şekli standart sapmalarının ölçüm seti sayısına göre değişimi

Çizelge 4 - Güncellenen rijitlik parametrelerinin ölçüm seti sayısına göre değişimi

\begin{tabular}{ccccccc}
\hline $\begin{array}{c}\text { Rijitlik } \\
\text { Parametresi }\end{array}$ & $\boldsymbol{N}_{\boldsymbol{s}}=\mathbf{5}$ & $\boldsymbol{N}_{\boldsymbol{s}}=\mathbf{1 0}$ & $\boldsymbol{N}_{\boldsymbol{s}}=\mathbf{1 5}$ & $\boldsymbol{N}_{\boldsymbol{s}}=\mathbf{2 0}$ & $\boldsymbol{N}_{\boldsymbol{s}}=\mathbf{2 5}$ & $\boldsymbol{N}_{\boldsymbol{s}}=\mathbf{3 0}$ \\
\hline$\theta_{1}$ & 0,98 & 0,99 & 1,00 & 1,00 & 1,00 & 1,07 \\
$\theta_{2}$ & 0,97 & 0,96 & 0,95 & 0,95 & 0,96 & 0,82 \\
$\theta_{3}$ & 0,94 & 0,94 & 0,94 & 0,94 & 0,95 & 0,91 \\
\hline
\end{tabular}

Çizelge $5-N_{s}=25$ için güncellenen rijitlik parametrelerinin sensör sayısı ve yerleşimine göre değişimi

\begin{tabular}{ccccccc}
\hline \multirow{2}{*}{$\begin{array}{c}\text { Rijitlik } \\
\text { Parametresi }\end{array}$} & $\mathbf{1}$ & $\mathbf{2}$ & $\mathbf{3}$ & $\mathbf{1 - 2}$ & $\mathbf{2 - 3}$ & $\mathbf{1 - 3}$ \\
\cline { 2 - 7 } & 0,67 & 0,48 & 0,68 & 0,98 & 0,99 & 1,12 \\
$\theta_{1}$ & 0,53 & 2,55 & 0,65 & 1,02 & 0,99 & 0,86 \\
$\theta_{2}$ & 0,78 & 0,38 & 1,33 & 0,91 & 0,92 & 0,81 \\
$\theta_{3}$ & & &
\end{tabular}

Uygulamada, özellikle büyük ölçekli yapılar için tüm serbestlik derecelerini ölçmek neredeyse imkansızdır. Hatta çoğu zaman, ancak çok kısıtlı bir alandan ölçüm almak mümkün olabilmektedir. Bu durumda elbette ki sunulan yöntemin optimizasyon aşamasında problem yaşaması beklenebilir. Yöntemin etkinliğini arttırmak için sayısal modelde dinamik 
yoğunlaştırma [30], optimal sensör yerleşimi [31,32] veya çoklu ölçüm grupları [22] gibi uygulamalara başvurmak mutlaka faydalı olacaktır. Bu açıdan, sunulan yöntemin etkinliğinin sensör sayısına bağlı değişimi, bahsedilen bu yöntemlerin herhangi birine başvurmadan, deneysel model üzerinden incelenmiştir. Bu doğrultuda, rijitlik parametrelerinin sensör yoğunluğu ve yerleşimine göre değişimi Çizelge 5'de sunulmaktadır. Burada, sensör sayısı azaldıkça, güncellenen parametrelerin nominal değerlerden $\left(\theta_{i}=1,00\right.$ 'den $)$ uzaklaştığı açıkça görülmektedir. Örneğin, yalnızca tek bir sensör kullanılması durumunda, mod şekillerinin katkısı hesaba katılamayacağı için problem tanılanamaz (unidentifiable) bir hale gelmektedir. Ancak, iki adet sensör kullanılması durumunda, sensör yerleşimine bağlı olarak oldukça makul sonuçların elde edildiği de görülebilmektedir.

\section{SONUÇLAR}

$\mathrm{Bu}$ çalışmada, sonlu eleman modellerinin maksimum olasılık tahmini ile güncellenmesine yönelik bir yaklaşım sunulmuştur. Önerilen yaklaşımda, ölçüm ve model hataları, mod şekillerinin çoklu ölçüm setlerinden elde edilen ikinci mertebe istatistiksel parametreleri ile orantılı kabul edilerek bir çözüm elde edilmektedir. Sunulan yaklaşımın etkinliği, bir adet sayısal ve bir adet de deneysel uygulama üzerinden incelenmiş ve yöntemin oldukça makul sonuçlar verdiği görülmüştür. Elde edilen başlıca bulgular aşağıdaki gibidir.

- Ölçüm süresinin makul ölçüde uzun olduğu ve belirgin bir ölçüm hatasının (kablo hatası ve/veya veri toplama düzeneğinden kaynaklı yüksek kanal gürültüsü) oluşmadığ durumlarda, ölçüm seti sayısı arttıkça elde edilen standart sapma değerleri azalmakta, başka bir deyişle her bir ölçüm setinde elde edilen lokal parametrelerin birer ortalaması olarak hesaplanan global modal parametrelerin kalitesi (gerçek değere olan yakınsaması) artmaktadır. Bu durum, doğal olarak güncellenen modal parametrelerin kalitesini de arttırmaktadır.

- Uygulamada, çoğu zaman yerince uzun kayıt süresine sahip çoklu ölçümler almak mümkün olmayabilmektedir. Öte yandan, eğer ölçüm setleri çok uzun bir zaman dilimi içerisinde tamamlanırsa, yapının modal parametrelerinde sıcaklık değişimi vb. etkiler nedeniyle oluşabilecek değişimler ciddi miktarda model hatalarına neden olabilir. Bu da hem ölçüm kalitesini hem de model güncelleme prosedürünü olumsuz yönde etkileyebilir. Bunun yerine daha kısa süreli (30,60 veya $90 d k$ gibi) ve tek seferde alınan kayıtlar, makul uzunlukta (3-5 $d k$ gibi) ölçüm setlerine ayrılabilir. Bu durumda, ölçüm seti sayısı arttıkça, ölçüm süresi kısalacağı için ölçüm hataları da artmaya devam edecektir. Bu nedenle optimal ölçüm seti sayısı, ölçüm hatalarının ölçüm seti sayısına göre değişimi göz önünde bulundurularak belirlenmelidir.

\section{Teşekkür}

Yazar, yüksek lisans tez çalışmasında kullandığı deney verilerini paylaşan İzmir Yüksek Teknoloji Enstitüsü, İnşaat Mühendisliği Bölümü Araştırma Görevlisi Hasan Ceylan'a ve Bölüm öğretim üyelerinden Doç. Dr. Gürsoy Turan’a katkılarından dolayı teşekkür eder. 


\section{Kaynaklar}

[1] Overschee, P.V., De Moor, B., Subspace algorithms for the stochastic identification problem, Automatica., 29, 649-660, 1993.

[2] Brincker, R., Zhang, L., Andersen, P., Modal identification of output-only systems using frequency domain decomposition, Smart Mater. Struct., 10, 441-445, 2001.

[3] Hermans, L., Van Der Auweraer, H., Guillaume, P., A frequency-domain maximum likelihood approach for the extraction of modal parameters from output-only data, Proc. 23rd Int. Conf. Noise Vib. Eng. ISMA. 963-972, 1998.

[4] Yuen, K.V., Katafygiotis, L.S., Bayesian Fast Fourier Transform Approach for Modal Updating Using Ambient Data, Adv. Struct. Eng., 6, 81-95, 2003.

[5] Katafygiotis, L.S., Yuen, K.V., Bayesian spectral density approach for modal updating using ambient data, Earthq. Eng. Struct. Dyn., 30, 1103-1123, 2001.

[6] Mevel, L., Basseville, M., Benveniste, A., Goursat, M., Merging sensor data from multiple measurement set-ups for non-stationary subspace-based modal analysis, J. Sound Vib., 249,719-741, 2002.

[7] Hizal, Ç., Turan, G., Aktaş, E., Ceylan, H., A mode shape assembly algorithm by using two stage Bayesian Fast Fourier Transform Approach, Mech. Syst. Signal Process., 134, 106328, 2019.

[8] Au, S.K., Fast Bayesian ambient modal identification in the frequency domain, Part I: Posterior most probable value, Mech. Syst. Signal Process., 26, 60-75, 2012.

[9] Yuen, K.V., Bayesian Methods for Structural Dynamics and Civil Engineering, 2010.

[10] Hizal, Ç., Modal identification of structures by using Bayesian statistics, Ph.D. Thesis, Izmir Institute of Technology, 2019.

[11] Beck, J.L., Au, S.K., Bayesian Updating of Structural Models and Reliability using Markov Chain Monte Carlo Simulation, J. Eng. Mech., 128, 380-391, 2002.

[12] Ching, J., Chen, Y., Transitional Markov Chain Monte Carlo Method for Bayesian Model Updating, Model Class Selection, and Model Averaging, J. Eng. Mech., 133, 816-832, 2007.

[13] Bansal, S., A New Gibbs Sampling Based Bayesian Model Updating Approach Using Modal Data From Multiple Setups, Int. J. Uncertain. Quantif., 5, 361-374, 2015.

[14] Cheung, S.H., Bansal, S., A new Gibbs sampling based algorithm for Bayesian model updating with incomplete complex modal data, Mech. Syst. Signal Process., 92, 156$172,2017$.

[15] Khodaparast, H.H., Mottershead, J.E., Friswell, M.I., Perturbation methods for the estimation of parameter variability in stochastic model updating, Mech. Syst. Signal Process., 22, 1751-1773, 2008.

[16] Abu Husain, N., Khodaparast H.H., Ouyang, H., Parameter selection and stochastic model updating using perturbation methods with parameter weighting matrix assignment, Mech. Syst. Signal Process., 32, 135-152,2012. 
[17] Hua, X.G., Ni, Y.Q., Chen, Z.Q., Ko, J.M., An improved perturbation method for stochastic finite element model updating, Int. J. Numer. Methods Eng., 73, 1845-1864, 2008

[18] Behmanesh, I., Moaveni, B., Lombaert, G., Papadimitriou, C., Hierarchical Bayesian model updating for structural identification, Mech. Syst. Signal Process., 64-65, 360376, 2015.

[19] Sedehi, O., Papadimitriou, C., Katafygiotis, L.S., Probabilistic hierarchical Bayesian framework for time-domain model updating and robust predictions, Mech. Syst. Signal Process., 123, 648-673, 2019.

[20] Yan, W.J., Katafygiotis, L.S., A novel Bayesian approach for structural model updating utilizing statistical modal information from multiple setups, Struct. Saf., 52, 260-271, 2015.

[21] Zhang, F.L., Ni, Y.C., Lam, H.F., Bayesian structural model updating using ambient vibration data collected by multiple setups, Struct. Control Heal. Monit., 24, 1-18, 2017.

[22] Hızal, Ç., Turan, G., A two-stage Bayesian algorithm for finite element model updating by using ambient response data from multiple measurement setups, J. Sound Vib., 469, $115139,2020$.

[23] Au, S.K., Zhang, F.L., Fundamental two-stage formulation for Bayesian system identification, Part I: General theory, Mech. Syst. Signal Process., 66-67, 31-42, 2016.

[24] Zhang, F.L., Au, S.K., Fundamental two-stage formulation for Bayesian system identification, Part II: Application to ambient vibration data, Mech. Syst. Signal Process., 66-67, 43-61, 2016.

[25] Shiradhonkar, S.R., Shrikhande, M., Seismic damage detection in a building frame via finite element model updating, Comput. Struct. 89, 2425-2438, 2011.

[26] MATLAB 2018a (Computer Software), MathWorks, Natick, MA, (2018).

[27] Zhang, L., Wang, T., Tamura, Y., A frequency-spatial domain decomposition (FSDD) method for operational modal analysis, Mech. Syst. Signal Process., 24, 1227-1239, 2010.

[28] Ceylan, H., Modal parameter identification of civil engineering structures by using an Output-Only System Identification Technique, M.Sc. Thesis, Izmir Institute of Technology, 2015.

[29] Ceylan, H., Turan, G., Hizal, Ç., Pre-Identification Data Merging for Multiple Setup Measurements with Roving References, Exp. Tech. 44, 435-456, 2020.

[30] Bansal, S., Bayesian model updating using modal data based on dynamic condensation, J. Eng. Mech. 146(2), 04019123, 2020.

[31] Papadimitriou, C., Lombaert, G., The effect of prediction error correlation on optimal sensor placement in structural dynamics, Mech. Syst. Signal Process. 28, 105-127, 2012.

[32] Papadimitriou, C., Optimal sensor placement methodology for parametric identification of structural systems, J. Sound Vib. 278, 923-947, 2004. 